\title{
Contexto, conteúdo e processo da mudança estratégica em uma empresa estatal do setor elétrico brasileiro*
}

\author{
Cláudia Fabiana Gohr** \\ Luciano Costa Santos***
}

SumÁrio: 1. Introdução; 2 . O fenômeno da mudança estratégica nas organizações; 3. Procedimentos metodológicos; 4. A mudança estratégica na Eletrosul Centrais Elétricas S.A.; 5. Conclusões.

Summary: 1.Introduction; 2 . The phenomenon of strategic change in organizations; 3. Methodological procedures; 4 . The strategic change in Eletrosul Centrais Elétricas S.A.; 5. Conclusions.

Palavras-chave: mudança estratégica; estratégia empresarial; setor elétrico brasileiro.

KEY WORDs: strategic change; corporate strategy; Brazilian electricity sector.

Este artigo apresenta os resultados de uma pesquisa que teve o objetivo de analisar as ações estratégicas realizadas por uma empresa estatal do setor elétrico brasileiro (SEB) e que levaram à mudança estratégica na organização durante o período 19902004. Para a consecução do objetivo, foram utilizadas as dimensões de contexto, conteúdo e processo, sugeridas por Pettigrew (1987) para pesquisas sobre mudança estratégica. A pesquisa caracteriza-se como um estudo de caso qualitativo com uma perspectiva de análise longitudinal. Os dados foram coletados por meio de entrevistas, observação direta e análise documental. Pôde-se concluir que o período que

\footnotetext{
* Artigo recebido em abr. 2010 e aceito em maio 2011.

** Doutora em engenharia de produção. Professora da Universidade Federal da Paraíba (UFPB). Endereço: Cidade Universitária, Centro de Tecnologia, Campus I, bl. G, Departamento de Engenharia de Produção - CEP 58051-970, João Pessoa, PB, Brasil. Caixa postal 5045. E-mail: claudiagohr@yahoo.com.br.

**** Doutor em engenharia de produção. Professor da UFPB. Endereço: Cidade Universitária, Centro de Tecnologia, Campus I, bl. G, Departamento de Engenharia de Produção — CEP 58051-970, João Pessoa, PB, Brasil. Caixa postal: 5045. E-mail: lucosantos@gmail.com.
} 
esta pesquisa contemplou foi de grande turbulência para o SEB e também para a firma, fazendo com que várias mudanças surgissem para modificar o comportamento estratégico da empresa e a sua competitividade, reveladas pela interação dinâmica entre contexto, conteúdo e processo. Embora a empresa faça parte de um ambiente altamente institucionalizado, que normalmente caracteriza o determinismo ambiental inerente ao SEB, a mudança estratégica na organização também ocorreu por meio de um processo voluntarista, caracterizado pela intenção gerencial de guiar o processo de mudança.

Context, content and process of the strategic change in a state-owned entreprise of the Brazilian electricity sector

This article presents the results of a research that aimed to analyze the strategic actions undertaken by a state enterprise of the Brazilian electric sector which led to strategic change in the organization during the period comprised between 1990 and 2004. In this way, were used the dimensions of context, content and process, as suggested by Pettigrew (1987) for research on strategic change. The research is characterized as a qualitative case study with a longitudinal perspective of analysis. Data were collected through interviews, direct observation and document analysis. It was concluded that the period analyzed in this research was very turbulent for the sector and also for the company, which led to several changes that modified the strategic behavior of the company and its competitiveness, revealed by the dynamic interaction between context, content and process. Although the company is part of a highly institutionalized environment, which normally characterizes the environmental determinism inherent in the Brazilian Electricity Sector, the strategic shift in the organization also occurred through a deliberate process, characterized by the managerial intention to guide the change process.

\section{Introdução}

O setor elétrico brasileiro (SEB) é considerado estratégico para o país, atuando diretamente na dinâmica de crescimento e desenvolvimento econômico. Devido à sua grande relevância e também à constante ameaça de novas crises de abastecimento de energia, o setor vem sofrendo uma série de modificações e reformas, tendo sido incluído como um dos pilares do Programa de Aceleração do Crescimento (PAC), instituído pelo governo federal no início de 2007.

A reestruturação do setor elétrico, iniciada na década de 1990, tem gerado mudanças significativas que alteram a organização industrial, o regime de propriedade das empresas, o funcionamento do mercado e a regulação setorial. Tais mudanças motivaram pesquisas que buscavam compreender as consequências advindas do processo de reestruturação do setor, conforme pode ser observado nos trabalhos de Bosquetti, Doria e Fernandes (2005), 
Vinhaes (2003) e Bernardes (2003). De certa forma, o surgimento de pesquisas sobre a reforma do SEB acompanhou uma tendência mundial, dado que outros países enfrentaram processos semelhantes, quase que simultaneamente ao caso brasileiro (Nelson e Dowling, 1998).

Diante dessa realidade de transformações e devido às incertezas que permeiam o SEB, ainda existem muitos aspectos para serem estudados no setor. Atualmente, muitas empresas do setor elétrico se encontram em uma posição de resistência às mudanças, ao mesmo tempo que são impelidas a desenvolver estratégias com o objetivo de ampliar sua competitividade. Para isso, porém, é essencial que as mesmas compreendam sua trajetória estratégica, de forma a fornecer subsídios para ações e decisões futuras.

Devido às questões apresentadas, as organizações do SEB tornam-se excelentes laboratórios para o estudo e a análise das mudanças estratégicas. Contribuindo para essa área, este trabalho apresenta os resultados de uma pesquisa que teve o objetivo de analisar as mudanças estratégicas ocorridas durante o período 1990-2004 na Eletrosul Centrais Elétricas S.A., uma empresa estatal do SEB. Para a consecução desse objetivo, foram utilizadas como arcabouço de análise as dimensões de contexto, conteúdo e processo, sugeridas por Pettigrew (1987) para pesquisas sobre mudança estratégica.

Considerando que grande parte das pesquisas sobre os processos de mudança enfoca as organizações privadas (Oliveira et al., 2009; Beugelsdijk, Slangen e Herpen, 2002; Hailey e Balogun, 2002; Massini et al., 2002; Child e Smith, 1987), a análise da mudança estratégica em uma empresa estatal revela peculiaridades que não são comumente abordadas na literatura da área. Entre outros fatores, a forte vinculação das estratégias da empresa com a política governamental representa uma variável crítica para estudos de mudança em empresas estatais, o que ressalta a relevância desta pesquisa.

Além deste texto introdutório, o artigo está estruturado em quatro partes principais. A próxima seção apresenta uma breve revisão de literatura sobre o conceito de mudança estratégica e suas diferentes visões. Em seguida, são discutidos os procedimentos metodológicos que orientaram a operacionalização da pesquisa de campo. Posteriormente, os resultados da análise são descritos e discutidos. Ao final, são apresentadas as principais conclusões e recomendações da pesquisa.

\section{0 fenômeno da mudança estratégica nas organizações}

A mudança faz parte da sociedade moderna e, consequentemente, das organizações. Por esse motivo, o termo "mudança" é tão utilizado em estudos 
organizacionais, gerando diversas linhas de pesquisa em torno do tema. Há bastante tempo, algumas linhas de pesquisa sobre mudança têm se preocupado com as modificações na estrutura organizacional (Chandler Jr., 1962), enquanto outras linhas têm abordado as questões comportamentais e culturais que fazem parte da mudança organizacional (Lawrence e Lorsch, 1972). Há também aquelas correntes que estudam as transformações nas estratégias empresariais (Agarwal e Helfat, 2009; Mintzberg e Westley, 1992). Em outras palavras: "mudança estratégica", o assunto em foco neste artigo.

As mudanças nas organizações podem ser provenientes de questões externas e internas. Dessa maneira, quando a empresa reage a essas questões, ela se adapta à nova situação. Segundo Schein (1982), a mudança pode ser concebida por meio de um ciclo adaptado que começa com uma modificação em algum aspecto do ambiente organizacional e termina em uma situação de equilíbrio mais adaptada e dinâmica para enfrentar tal modificação. O processo de mudança estratégica pode ser concebido como um processo de aprendizado em que a organização está continuamente reavaliando sua relação com o ambiente externo, de forma a encontrar uma posição de equilíbrio. O processo de mudança estratégica tem escopo amplo e traz impactos de longo prazo, envolvendo variáveis críticas da organização, como a política, a cultura, as relações de poder, a distribuição de recursos, entre outras (Hutt, Walker e Frankwick, 1995).

Quinn e Voyer (2001) consideram que a mudança estratégica é um processo fragmentado, evolucionário e intuitivo, em que novas estratégias fluem à medida que decisões internas e eventos externos aparecem juntos para criar um novo contexto. A mudança estratégica focaliza as transformações que ocorrem na direção da empresa (Mintzberg e Westley, 1992), levando as organizações a modificarem suas estratégias em função de eventos externos e/ou internos que influenciam tal transformação.

As organizações podem mudar sua estratégia de maneira incremental ou radical. As transformações no modo incremental se dão em aspectos específicos da organização, fazendo com que a mudança ocorra em pequenos passos durante longos períodos, permitindo que as empresas aprendam por meio de suas ações iniciais. Já nas mudanças radicais, muitas variáveis organizacionais podem mudar ao mesmo tempo. Esse tipo de mudança é de alto impacto e provoca transformações profundas na firma, principalmente na estrutura, nas relações de poder e no processo decisório (Beugelsdijk, Slangen e Herpen, 2002; Mintzberg, Ahlstrand e Lampel, 2000; Pettigrew, 1992; Miller e Friesen, 1982). 
Coram e Burnes (2001) e Mintzberg e Westley (1992) afirmam que a mudança estratégica pode ocorrer de maneira planejada (deliberada) ou não planejada (emergente). Assim, as organizações podem gerenciar as mudanças formalmente, através de um processo de planejamento deliberado e dedutivo, caracterizando a mudança planejada. As organizações também podem gerenciar as mudanças informalmente, ou seja, emergentemente. Essa outra maneira trabalha com a suposição de que a mudança estratégica é um processo contínuo de adaptação, de acordo com as transformações impostas pelo ambiente incerto.

Do ponto de vista do conteúdo da mudança, March (1991) propõe dois conceitos que ajudam a compreender a mudança estratégica nas organizações: exploração (exploration) e explotação (exploitation). Segundo o autor, esses conceitos dizem respeito às ações que são implementadas pelas organizações e que podem levar à mudança estratégica, principalmente em função da modificação que ocorre na direção ou no caminho da empresa.

De acordo com March (1991), a essência das ações de exploração é a experimentação de novas alternativas, e seus retornos são incertos, distantes e frequentemente negativos. Por outro lado, organizações que utilizam ações estratégicas de explotação provavelmente encontram um equilíbrio estável, no que diz respeito ao contexto em que estão inseridas. Sua essência é o refinamento e a extensão das competências existentes, e seus retornos geralmente são positivos, de curto prazo e previsíveis. De acordo com March (1991), a sobrevivência da organização depende de uma abordagem equilibrada entre as ações de exploração e de explotação, pois ambas são necessárias à dinâmica organizacional. O quadro 1 apresenta algumas características das ações de exploração e de explotação.

Quadro 1

\section{Características das ações estratégicas de explotação e exploração}

\begin{tabular}{|ll|}
\hline Ações estratégicas de exploração & Açães estratégicas de explotação \\
\hline - Exploração de novas oportunidades. & - Explotação de "velhas certezas", ou seja, \\
- São autônomas, pois emergem da exploração & aspectos que já fazem parte dos recursos e das \\
de aspectos que estão fora do escopo da & competências da organização. \\
estratégia atual da firma. & São induzidas, pois estão dentro do escopo da \\
- Estão relacionadas à procura, riscos, & estratégia atual da firma. \\
$\begin{array}{l}\text { experimentação, flexibilidade, descobertas e } \\
\text { inovações. }\end{array}$ & $\begin{array}{l}\text { Estão relacionadas ao refinamento, escolha, } \\
\text { produção, eficiência, seleção, implementação e } \\
\text { execução. }\end{array}$ \\
\hline
\end{tabular}

Fonte: elaborado pelos autores. 
As ações de exploração e de explotação são essenciais para as empresas, embora elas tenham de competir pelos mesmos recursos, que na maioria das vezes são escassos para todas as organizações. Assim, as organizações fazem escolhas explícitas e implícitas entre as duas ações. As escolhas explícitas são encontradas em decisões calculadas sobre alternativas de investimento e estratégias competitivas. Já as implícitas estão embutidas nas características organizacionais, isto é, nos procedimentos, nas práticas e nos meios pelos quais os objetivos são fixados e alcançados. Além disso, com a experiência, as empresas aprendem a dividir os recursos entre as ações de explotação e de exploração (March, 1991).

De outro ponto de vista, a mudança estratégica pode ser resultante de um processo voluntarista ou determinista (Astley e Van de Ven, 1983), ou seja, pode ser dirigida por intenção gerencial ou por pressões ambientais e institucionais. Segundo Astley e Van de Ven (1983), na orientação voluntarista os indivíduos são considerados autônomos, proativos e agentes que dirigem a mudança. Assim, os indivíduos são considerados os recursos de mudança na organização, e as organizações exercem livremente suas escolhas estratégicas. Dessa forma, as firmas podem e fazem a mudança acontecer, superando sua rigidez natural. De acordo com essa orientação, as atividades estratégicas de sucesso podem ser diferenciadas e surgem a partir da exploração de novas competências (Volberda, Baden-Fuller e Van den Bosch, 2001).

$\mathrm{Na}$ orientação determinista, o foco está sobre as propriedades estruturais do contexto no qual as ações estratégicas são reveladas. $\mathrm{O}$ ambiente tem grande poder e exerce influência na efetividade das organizações, fazendo com que os tomadores de decisão tenham pouca ou nenhuma capacidade de diminuir o poder do ambiente (Astley e Van de Ven, 1983). A orientação determinista encara a mudança estratégica como uma consequência das restrições provocadas pela escassez de recursos, convergente com as normas da indústria e com a inércia estrutural. De acordo com essa orientação, as atividades estratégicas de sucesso das empresas são muito similares e restritas ao fortalecimento e exploração de suas competências essenciais existentes (Volberda, Baden-Fuller e Van den Bosch, 2001).

A mudança estratégica também pode ser analisada por meio de três dimensões integradas, propostas por Pettigrew (1987, 1992): "contexto", "conteúdo" e "processo". A dimensão do contexto está relacionada ao "porquê" da mudança e é derivada da análise do ambiente interno e externo da organização. Em outras palavras, o contexto refere-se às forças ambientais e aos aspectos internos que restringem e habilitam as mudanças estratégicas no nível da firma. O conteúdo está relacionado ao "o quê" da mudança e pode 
estar relacionado ao equilíbrio das ações de exploração e de explotação. Na realidade, o conteúdo corresponde às estratégias que são, de fato, realizadas. O processo, por sua vez, diz respeito ao "como" da mudança (isto é, à maneira em que ela ocorre) e está relacionado ao caráter dinâmico e temporal da mudança estratégica. A visão do processo está alinhada ao conceito de formação da estratégia (Mintzberg, 1978), que leva em consideração a trajetória da organização e as diferentes maneiras que conduzem uma empresa para uma estratégia.

A tríade contexto-conteúdo-processo não representa apenas uma forma de explicar o fenômeno da mudança estratégica. A teoria proposta por Pettigrew (1987) fornece uma estrutura metodológica que permite guiar a pesquisa na área e correlacionar diferentes variáveis pertencentes a cada uma das três dimensões. Dessa forma, é possível dispor de uma abordagem integrada de análise, tão valorizada atualmente nos estudos organizacionais.

Enfim, podemos encontrar na literatura várias correntes de pensamento que explicam o fenômeno da mudança estratégica nas organizações. No entanto, essas diferentes abordagens não são mutuamente excludentes, pois consideram diferentes variáveis e dimensões organizacionais. Dessa maneira, pode-se afirmar que não existe um único caminho para gerenciar e estudar a mudança estratégica, sendo necessário, inclusive, que em determinadas pesquisas sejam utilizadas diferentes técnicas e métodos para analisar e compreender melhor como ocorre esse processo nas organizações.

Na seção a seguir, são discutidos os principais aspectos metodológicos que guiaram o desenvolvimento desta pesquisa.

\section{Procedimentos metodológicos}

A unidade de análise desta pesquisa é uma organização estatal do SEB, denominada Eletrosul Centrais Elétricas S.A., que atua na região Sul e no estado de Mato Grosso do Sul. A escolha da empresa se deu por alguns motivos, entre os quais:

1. foi a primeira empresa a ser cindida no país, depois da implantação do novo modelo do SEB;

2. é uma empresa relativamente antiga, o que possibilita o estudo e a análise de vários aspectos relacionados à mudança estratégica;

3. de uma forma geral, as organizações pertencentes ao SEB têm procurando aumentar sua competitividade, pois atualmente operam em um ambiente 
dinâmico e turbulento, no qual as regras institucionais têm mudado com bastante frequência.

Para entender com profundidade a mudança estratégica na empresa selecionada, optou-se pelo método do estudo de caso, utilizando uma abordagem qualitativa de análise. Segundo Yin (1994), o estudo de caso demanda uma pesquisa empírica que investiga um fenômeno contemporâneo dentro do contexto da vida real, especialmente quando os limites entre o fenômeno e o contexto não são claramente evidentes.

Considerando que a compreensão do fenômeno da mudança estratégica depende da obtenção de dados referentes a um determinado período de tempo (Van de Ven, 1992), esta pesquisa utilizou-se de uma análise longitudinal. Sem uma análise deste tipo, seria impossível identificar a dinâmica processual da mudança, a relação entre forças de continuidade e de mudança e, portanto, a inseparável ligação entre estrutura e processo (Pettigrew, 1985).

Em relação à dimensão temporal, foi delimitado um período de análise de 15 anos (1990-2004). Durante esse período, ocorreu uma série de mudanças de regras no setor elétrico e no contexto econômico do país. No início da década de 1990, foi editada uma Medida Provisória (no 115) que logo em seguida se transformou na Lei no 8.031, que estabelecia o Programa Nacional de Desestatização (PND). Esse programa foi o ponto de partida para um amplo conjunto de mudanças no cenário econômico brasileiro, ocasionando implicações de ordem macro e microeconômica. Para facilitar a análise, foram feitos cortes transversais que representam as mudanças na Presidência da República: 1990-92; 1993/94; 1995-2002; 2003/04. Pelo fato de a Eletrosul ser uma empresa estatal que atua em um setor sujeito à regulamentação governamental, a transição da equipe de governo passa a ser um dado relevante para a análise da mudança estratégica.

Para coletar as evidências empíricas no estudo do caso foram utilizados documentos que traziam dados setoriais e macroambientais, documentos da empresa, entrevistas semiestruturadas e observação direta. As mudanças estratégicas foram analisadas pela perspectiva do grupo de pessoas responsáveis pela tomada de decisão estratégica na organização (isto é, o grupo da alta direção). Para isso, foram entrevistados os diretores-presidentes que exerceram seus cargos durante o período de análise e também alguns funcionários ligados ao processo decisório de nível estratégico.

Para analisar a mudança estratégica na Eletrosul, foram utilizadas as dimensões de contexto, conteúdo e processo, propostas por Pettigrew (1987, 1992). As categorias de análise em cada uma dessas dimensões podem ser visualizadas na figura 1. 
Figura 1

Modelo de análise de contexto, conteúdo e processo

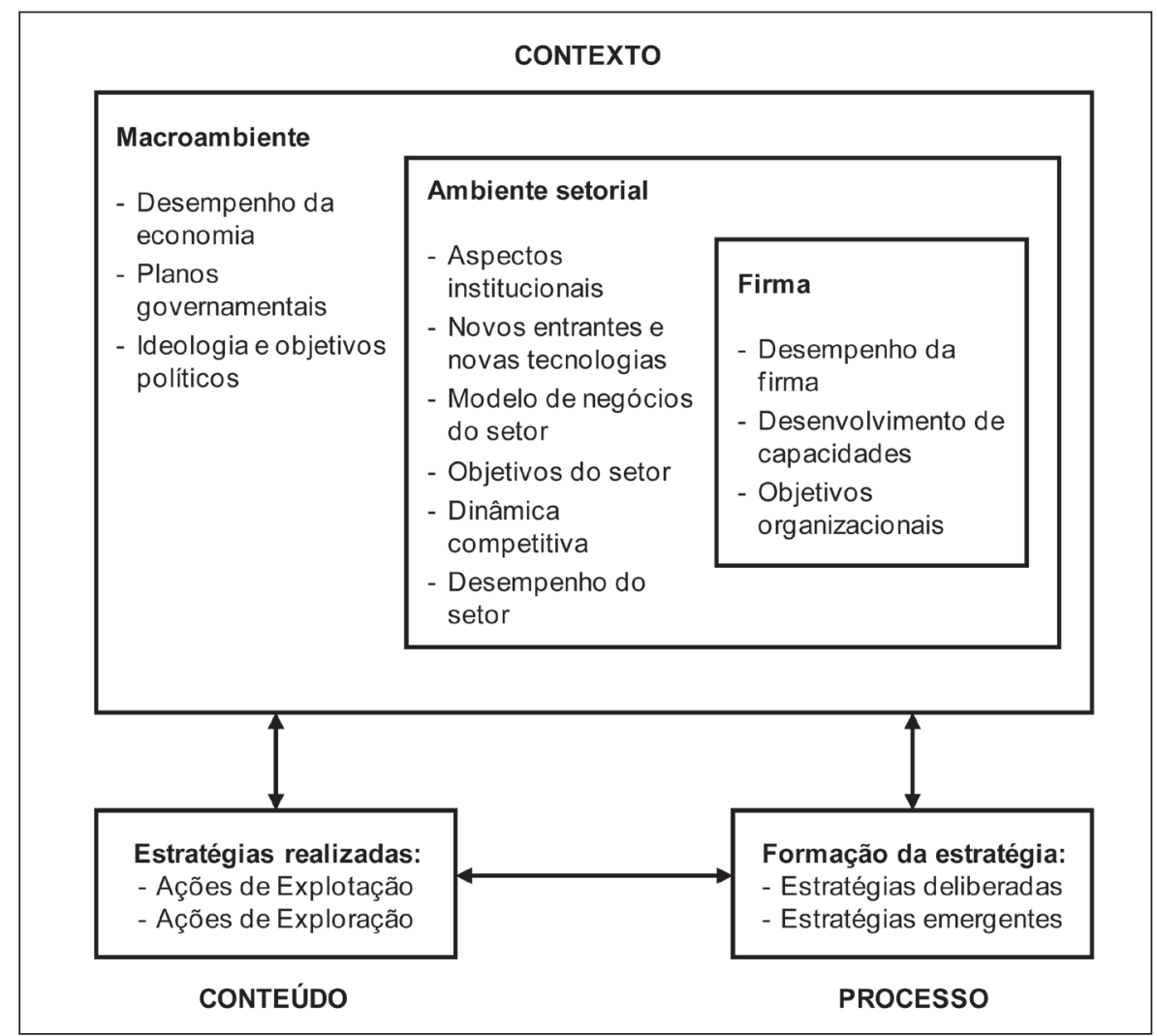

Fonte: elaborado pelos autores.

A seguir, são descritas as categorias de análise selecionadas para a pesquisa de campo.

a.1) Contexto externo - macroambiente: conjunto dos fatores que afetam os diferentes setores econômicos. Aspectos analisados:

v desempenho da economia - informações relacionadas ao desempenho econômico do país, que estimularam ou não a necessidade de mudanças no quadro macroambiental, ou seja, nos planos dos governos, na ideologia e nos objetivos políticos;

、 planos governamentais - informações relacionadas aos planos e programas adotados pelos governos;

、 ideologia e objetivos políticos - (i) ideologia: postura adotada pelo governo em relação à sua atuação na economia; (ii) objetivos políti- 
cos: metas adotadas pelo governo em relação à economia e que são formulados de acordo com a postura ideológica e com base no desempenho econômico do país.

a.2) Contexto externo - ambiente setorial: conjunto dos fatores que afetam diretamente a organização e seus concorrentes. Aspectos analisados:

$\checkmark$ aspectos institucionais - informações relacionadas às instituições que regem o setor e seus aspectos regulatórios;

$\checkmark$ novos entrantes e novas tecnologias - informações relacionadas aos aspectos não institucionais que se referem à entrada ou não de novas empresas no setor e à adoção ou não de novas tecnologias por parte das empresas;

$\checkmark$ modelo de negócios do setor - informações relacionadas à maneira pela qual as empresas são organizadas e também à forma de operação dessas empresas no setor;

v objetivos do setor - informações relacionadas às metas estabelecidas para o setor. No Brasil, os objetivos setoriais são provenientes dos aspectos macroambientais, geralmente estabelecidos nos Planos de Gestão Pública e nos Planos Plurianuais elaborados pelo Ministério do Planejamento, Orçamento e Gestão;

v dinâmica competitiva — informações relacionadas à forma de competição no setor;

$\checkmark$ desempenho do setor - informações relacionadas aos investimentos no setor, ao regime tarifário, ao consumo de energia, ao resultado das empresas etc.

a.3) Contexto interno - firma: conjunto dos fatores específicos da organização estudada. Aspectos analisados:

v desempenho da firma - foram levantadas informações relacionadas apenas ao desempenho econômico-financeiro da firma em análise, como: lucro ou prejuízo econômico, grau de endividamento etc.

v desenvolvimento de capacidades - seguindo a linha de visão baseada em recursos (Barney, 2001; Peteraf, 1993), esta pesquisa considera que as capacidades (capabilities) estão relacionadas aos diferentes recursos que as empresas possuem e à maneira pela qual elas coordenam esse conjunto de recursos; 
- objetivos organizacionais - informações relacionadas às metas estabelecidas para a empresa, que poderão estar em consonância com os aspectos dos contextos externo e interno.

b) Conteúdo: identificação das ações estratégicas realizadas pela empresa, ou seja, o "o quê" da mudança. Essas ações podem ser caracterizadas como ações de explotação e de exploração, que significam:

- ações estratégicas de explotação - estão dentro do escopo da atual estratégia da firma. Geralmente estão relacionadas a refinamentos de capacidades existentes e melhoria da eficiência;

v ações estratégicas de exploração - emergem da exploração de aspectos que estão fora do escopo da atual estratégia da firma, resultando da busca de novas oportunidades. Estão relacionadas a ações prospectivas que podem envolver riscos, experimentação e inovações.

c) Processo: esta dimensão se refere ao caráter dinâmico e temporal das ações estratégicas. Procurou-se identificar "como" as ações estratégicas foram realizadas pelas firmas, utilizando, para isso, o conceito de estratégias deliberadas e estratégias emergentes (Mintzberg e Westley, 1992; Mintzberg, 1978).

Com a definição das categorias de análise e dos aspectos específicos que deveriam ser investigados, foi possível iniciar a pesquisa de campo, cujos resultados são apresentados na próxima seção.

\section{A mudança estratégica na Eletrosul Centrais Elétricas S.A.}

Esta seção está dividida em três subseções. Inicialmente, é relatado um breve histórico que fundamenta a análise da mudança estratégica apresentada na subseção posterior. A terceira subseção discute os principais resultados da pesquisa, sintetizando a análise realizada.

\subsection{Antecedentes históricos}

Para compreender melhor as mudanças no SEB e na Eletrosul, procurou-se coletar dados em fontes documentais que pudessem contextualizar o ambiente externo no período que antecedeu o período de análise (1990-2004), desde o surgimento do setor elétrico em 1879. Para isso, foram estudados os aspectos macroambientais e setoriais definidos na seção anterior e reunidos em uma síntese histórica que é apresentada nos quadros 2 e 3. 


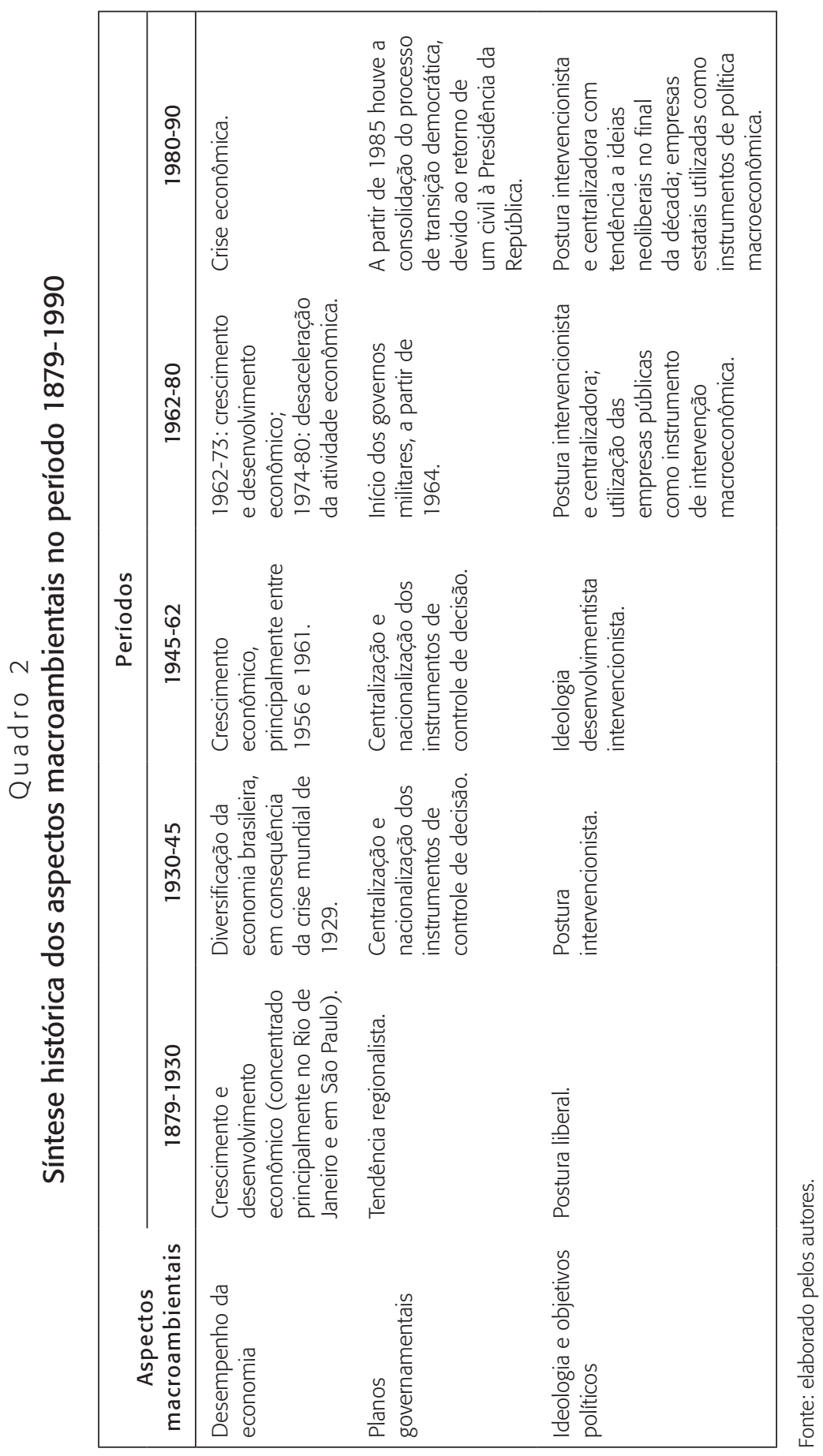




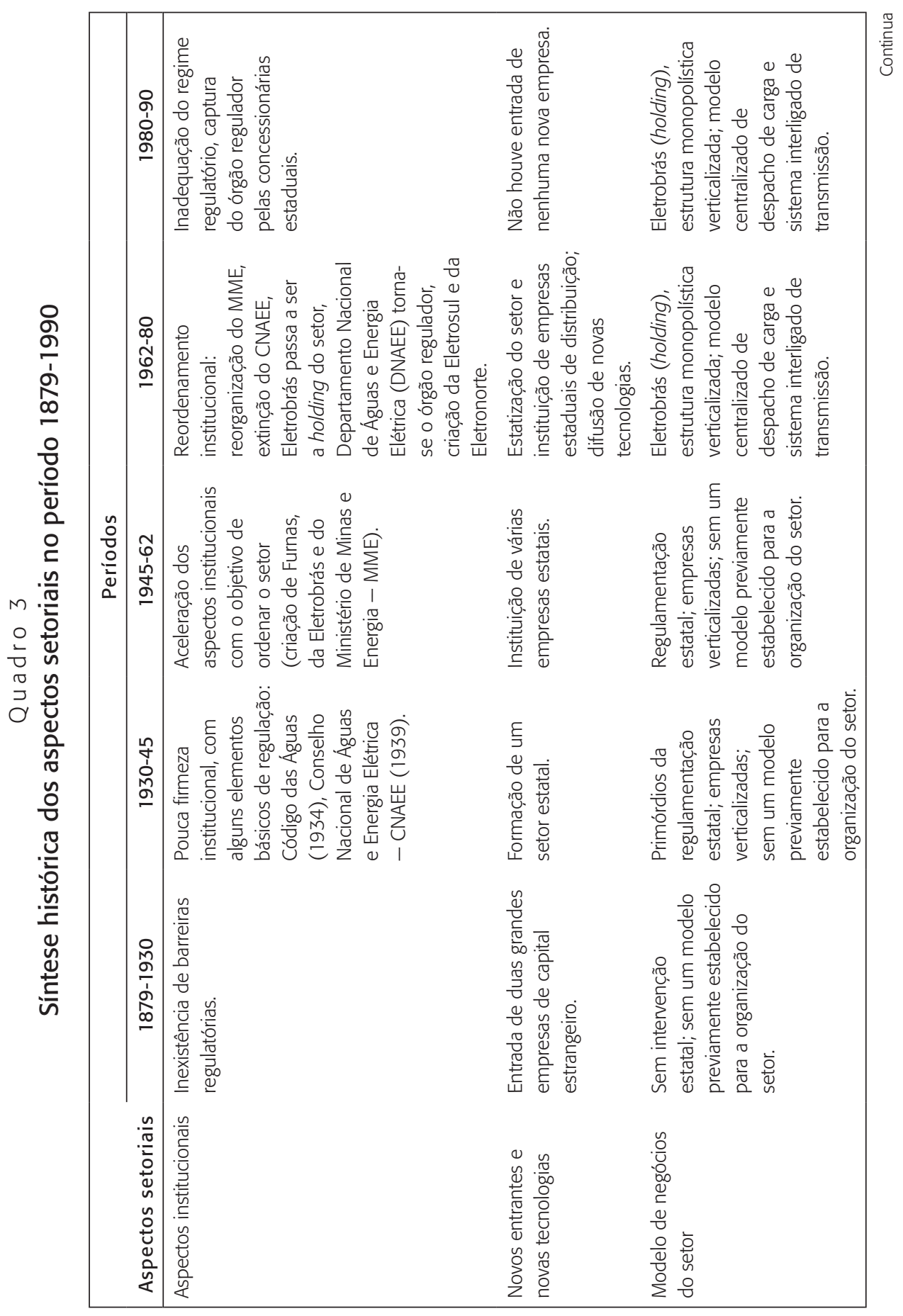




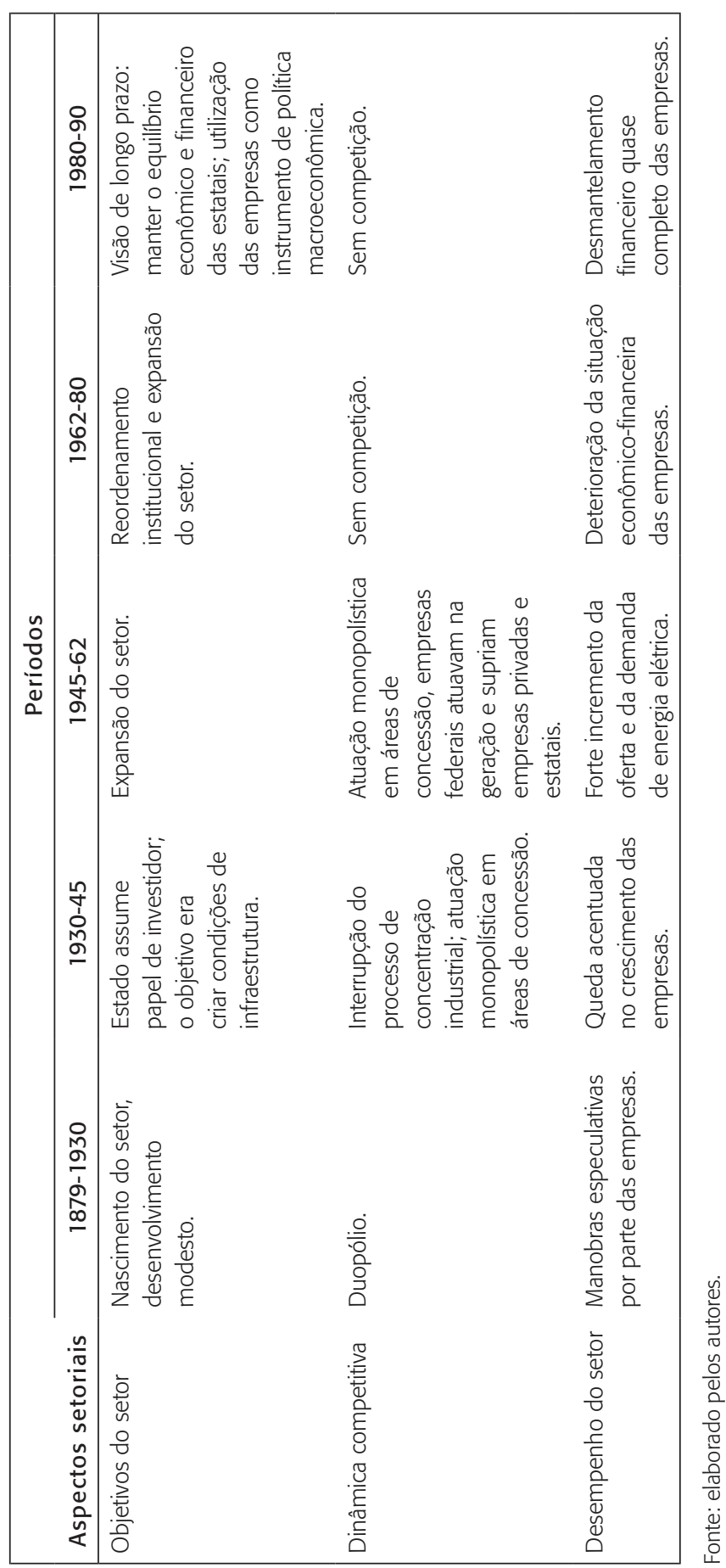

RAP - RIO DE JANEIRO 45(6):1673-1706, NOV./DEZ. 2011 
A análise da evolução do SEB demonstra a relação intrínseca entre o macroambiente e o ambiente setorial, fator que também foi observado na pesquisa de Gomes e Vieira (2009). A busca de informações históricas sobre o SEB e sobre o macroambiente possibilitou uma contextualização geral que favoreceu a construção das questões de pesquisa que nortearam a coleta de dados específicos da empresa.

No entanto, para que a contextualização fosse completa, foram coletadas informações sobre a criação da Eletrosul em 1968 e sua evolução até 1990, período anterior ao tempo delimitado para a análise da mudança estratégica. Os principais acontecimentos históricos da empresa podem ser resumidos no quadro 4, que relaciona esses eventos com as fases correspondentes do SEB.

Quadro 4

Breve histórico da empresa

\begin{tabular}{|c|c|}
\hline Fases do SEB & Acontecimentos \\
\hline $\begin{array}{l}\text { 1962-80: } \\
\text { Institucionalização do } \\
\text { setor }\end{array}$ & $\begin{array}{l}\text { A Eletrosul foi criada em 1968, como sociedade de economia mista com sede } \\
\text { em Brasília e com escritório central no Rio de Janeiro. Havia nesse período um } \\
\text { acelerado crescimento econômico, conforme pode ser observado no quadro } 2 . \\
\text { A empresa incorporou usinas de geração térmica sob controle federal e era de } \\
\text { sua responsabilidade desenvolver projetos de novas usinas hidrelétricas e de } \\
\text { transmissão regional. Tinha por objetivos realizar estudos e projetos, construir e } \\
\text { operar usinas produtoras e linhas de transmissão de energia elétrica na região } \\
\text { Sul do país. Em 1978, a sede da empresa foi transferida para Florianópolis } \\
\text { (SC), que passou a centralizar suas atividades administrativas. }\end{array}$ \\
\hline $\begin{array}{l}\text { 1980-90: } \\
\text { Crise econômica e } \\
\text { setorial }\end{array}$ & $\begin{array}{l}\text { Em 1986, foi criado o Conselho de Administração. A partir do final da década } \\
\text { de 1980, os trabalhos de geração ficaram praticamente paralisados, limitando- } \\
\text { se apenas à manutenção dos equipamentos já existentes. A empresa recorreu } \\
\text { a empréstimos com juros elevados, enfrentando problemas no fluxo de caixa e } \\
\text { elevação de seu grau de endividamento. }\end{array}$ \\
\hline
\end{tabular}

Fonte: elaborado pelos autores.

\subsection{A mudança estratégica no período 1990-2004}

A partir da década de 1990, a Eletrosul enfrentou uma sucessão de mudanças impulsionadas pela conjuntura econômica e política do país. Nesta época, o Brasil iniciou uma série de transformações que trouxeram impactos de âmbito macroeconômico e microeconômico. Em especial, o presidente Fernando Collor de Mello, em exercício no período 1990-92, deu início a um novo 
programa de governo que culminou em redução dos investimentos internos e contenção drástica das despesas públicas. Esse plano também abriu o país comercialmente para o mercado internacional.

O Programa Nacional de Desestatização (PND), editado inicialmente pela Medida Provisória ㄲo 115 e transformado posteriormente na Lei oㅡ 8.031, foi o ponto de partida para uma série de mudanças. Em âmbito macroeconômico, o PND proporcionou um grande impacto fiscal para os cofres públicos. Em relação aos aspectos microeconômicos, o PND estimulou a necessidade de melhorar as instituições e o aparato legal de regulação de diversos setores, entre eles, o SEB.

O PND tinha como um de seus principais objetivos a "reordenação da posição estratégica do Estado na economia, transferindo à iniciativa privada atividades indevidamente exploradas pelo setor público" (Velasco Júnior, 1997a, 1997b). Ao Banco Nacional de Desenvolvimento Econômico e Social (BNDES) ficou reservada a tarefa de administração do PND e da implementação das diretrizes determinadas pela comissão de privatização das empresas estatais (Pinheiro e Giambiagi, 2000).

As mudanças no contexto macroambiental, iniciadas na década de 1990, surtiram efeitos em diferentes setores da economia, em especial, nos setores de infraestrutura, tais como o setor elétrico. Para ilustrar essas mudanças, o quadro 5 destaca os aspectos relevantes do macroambiente que influenciaram direta ou indiretamente nas ações estratégicas implementadas pela organização em análise no período 1990-2004.

Entre os aspectos macroambientais que impulsionaram as transformações na Eletrosul (quadro 5), destaca-se a mudança na postura ideológica do governo, consequência dos princípios do Consenso de Washington, que resultou na formulação do PND.

No período 1990-92, o SEB passou por uma forte crise impulsionada principalmente pela crise política, econômica e social do país. A crise do petróleo, a dívida pública e a utilização do setor por grupos de interesse (Souza, 2002) também tiveram influência no SEB, prejudicando o alcance dos objetivos políticos. A redução da presença do Estado na economia e o início dos rumores das privatizações alteraram a relação de investimento-financiamento, embora grande parte dos financiamentos ainda ocorresse por meio de recursos públicos, pois as empresas eram caracterizadas, até 1995, como monopólios naturais, com consumidores cativos e tarifas reguladas. 


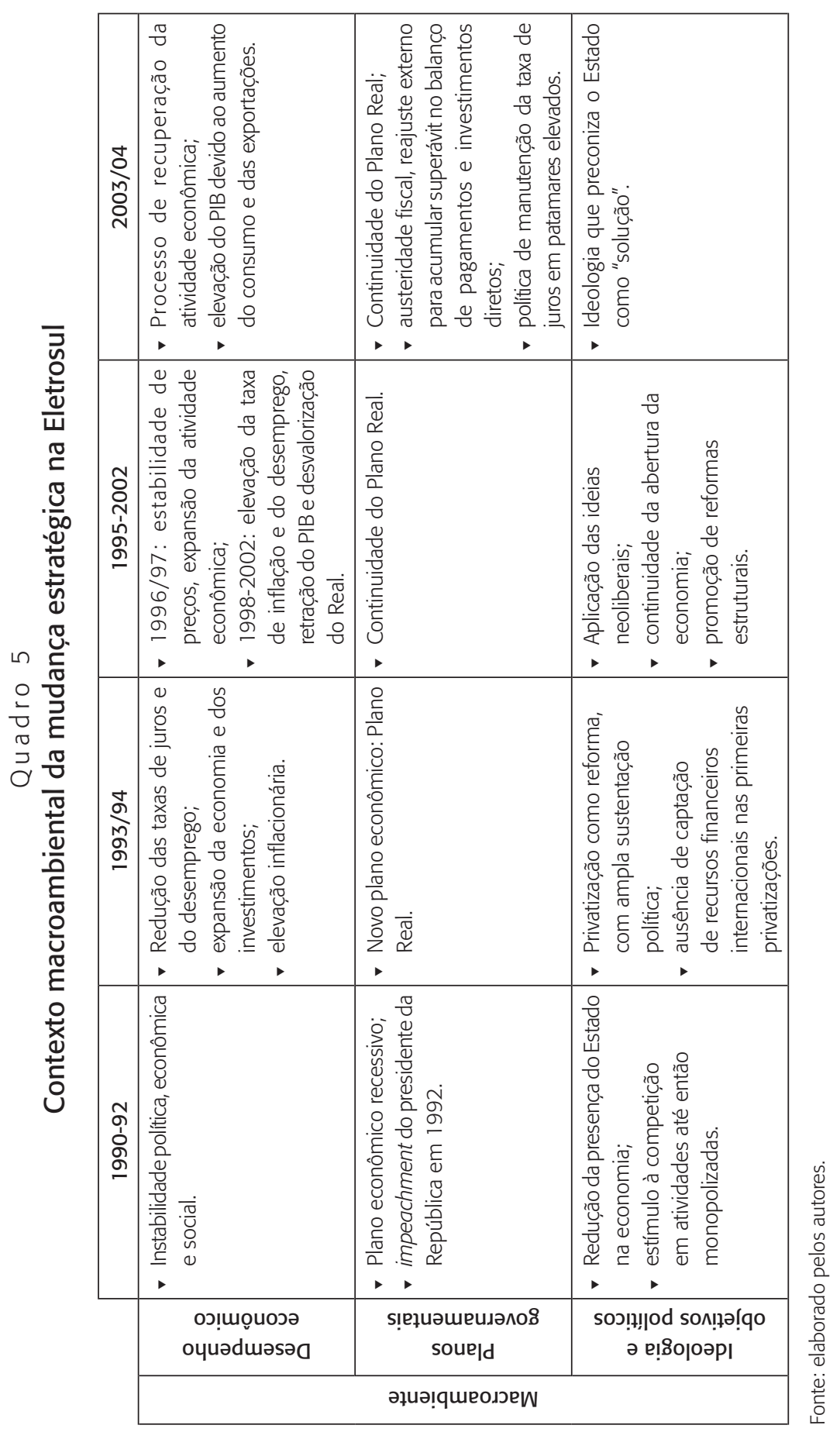


Os monopólios estatais apresentavam ineficiência econômica, vulnerabilidade a reveses financeiros e serviço da dívida elevado, indicando uma potencial falha no modelo de negócios do setor. Nesse sentido, o objetivo do setor era encontrar um modelo de negócios mais eficiente.

Em 1993 foi estabelecido um novo regime tarifário para as empresas do SEB (Lei no 8.631), foi permitida a formação de consórcios de geração hidrelétrica entre as concessionárias de energia e os autoprodutores (Decreto no 913) e foi criado o Sistema Nacional de Transmissão de Energia Elétrica (Sintrel) (órgão que permitiria o desenvolvimento dos mercados atacadistas de energia elétrica), caracterizando os aspectos institucionais no período 1993/94 (Bernardes, 2003; Pires, 2000). Tais aspectos representaram o marco inicial de reforma do SEB. Como consequência da Lei oㅡ 8.631, as tarifas passaram a ser reajustadas acima da inflação, contribuindo, dessa forma, para a formação de uma perspectiva positiva de crescimento para o setor.

As empresas começaram a perceber a rapidez das inovações tecnológicas e procuraram realizar parcerias para dar continuidade às suas obras e expandir o campo de prestação de serviços. Segundo Cartemol (2004), a capacidade das empresas de realizar investimentos e inovações era vital para o desempenho do mercado, pois aumentava a pressão competitiva, o que poderia resultar em maior eficiência do SEB.

Em 1995 houve a primeira privatização do setor e, a partir de então, ocorreram vários processos de privatização de empresas de energia. Portanto, o período 1995-2002 foi caracterizado por um processo de transformação radical nos aspectos institucionais, que se refletiu: (i) na entrada de novos agentes no mercado; (ii) em mudanças nas inovações tecnológicas; (iii) em um novo modelo de negócios do setor; (iv) nos objetivos do setor; (v) na dinâmica competitiva; (vi) em seu desempenho.

No ano de 2000, as privatizações tiveram uma redução substancial, e as empresas tiveram uma diminuição real de seus ativos, consequência do cenário macroambiental do período. Embora muitas privatizações tivessem ocorrido no período 1995-2002, tais privatizações se deram antes que as regras do mercado estivessem bem definidas e antes que as instituições tivessem sido totalmente criadas.

De acordo com o novo modelo de negócios proposto para o setor, o financiamento das empresas seria via recursos públicos (BNDES) e privados; as concessionárias foram divididas em atividades de geração, transmissão, distribuição e comercialização; houve a abertura do mercado para grupos priva- 
dos; foi iniciada a competição na comercialização e na geração de energia; os consumidores passaram a ser livres e cativos; e os preços começaram a ser livremente negociados na geração e na comercialização. Entretanto, tal modelo apresentou algumas falhas no ano 2000, resultando em crise de abastecimento nos anos 2001/02. Dessa forma, o SEB passou a ser considerado um gargalo para o crescimento econômico, principalmente pela ausência de crescimento da oferta de energia.

A política de privatização e o novo modelo de negócios do setor implementados no período 1995-2002 não apresentaram os resultados esperados; assim, a partir de 2003 o governo voltou a reforçar o papel do setor público no planejamento e na regulação setorial (como consequência dos objetivos e da ideologia política). Dessa forma, foram feitas algumas modificações nos marcos regulatórios já estabelecidos, e as empresas controladas pela Eletrobrás foram retiradas do PND. Tais mudanças procuravam reduzir a escassez de energia nos anos posteriores e também diminuir a incerteza dos agentes privados, possibilitando o aumento dos investimentos no setor.

Devido à impossibilidade de entrada de novas empresas no mercado, aumentaram os entraves à concorrência, embora houvesse a possibilidade de parcerias público-privadas (PPPs) (Fiocca, 2004).

Foram vários os aspectos que prejudicaram o desempenho do SEB no período de 2002/03, tais como (Azeredo, 2004): (i) o desmantelamento do sistema nacional de planejamento; (ii) a realização de um acelerado (e pouco planejado) trabalho de desregulamentação; (iii) a não observância de aspectos fundamentais dos processos de privatização, como as garantias mínimas que eram necessárias para a efetivação dos investimentos. Enfim, esses problemas, somados à falta de crédito por parte das empresas e também às incertezas do modelo anterior, resultaram no desempenho negativo do setor nos anos 2003/04. Além disso, nos processos de privatização não existia nenhum condicionamento que obrigava as empresas privatizadas a investir.

Os aspectos do ambiente setorial que influenciaram na firma objeto de estudo podem ser visualizados de forma resumida no quadro 6 .

No período 1990-92, o SEB estava em crise e, como consequência, o desempenho da Eletrosul foi considerado negativo, pois acumulava prejuízos devido à falta de recursos do governo federal. Como os investimentos destinavam-se apenas à manutenção das instalações existentes, o desenvolvimento de capacidades ficou aquém do que se esperava. Em função de seu desempenho negativo, a firma estabeleceu como objetivos no período 1990-92 a restrição orçamentária e a redução dos custos. 


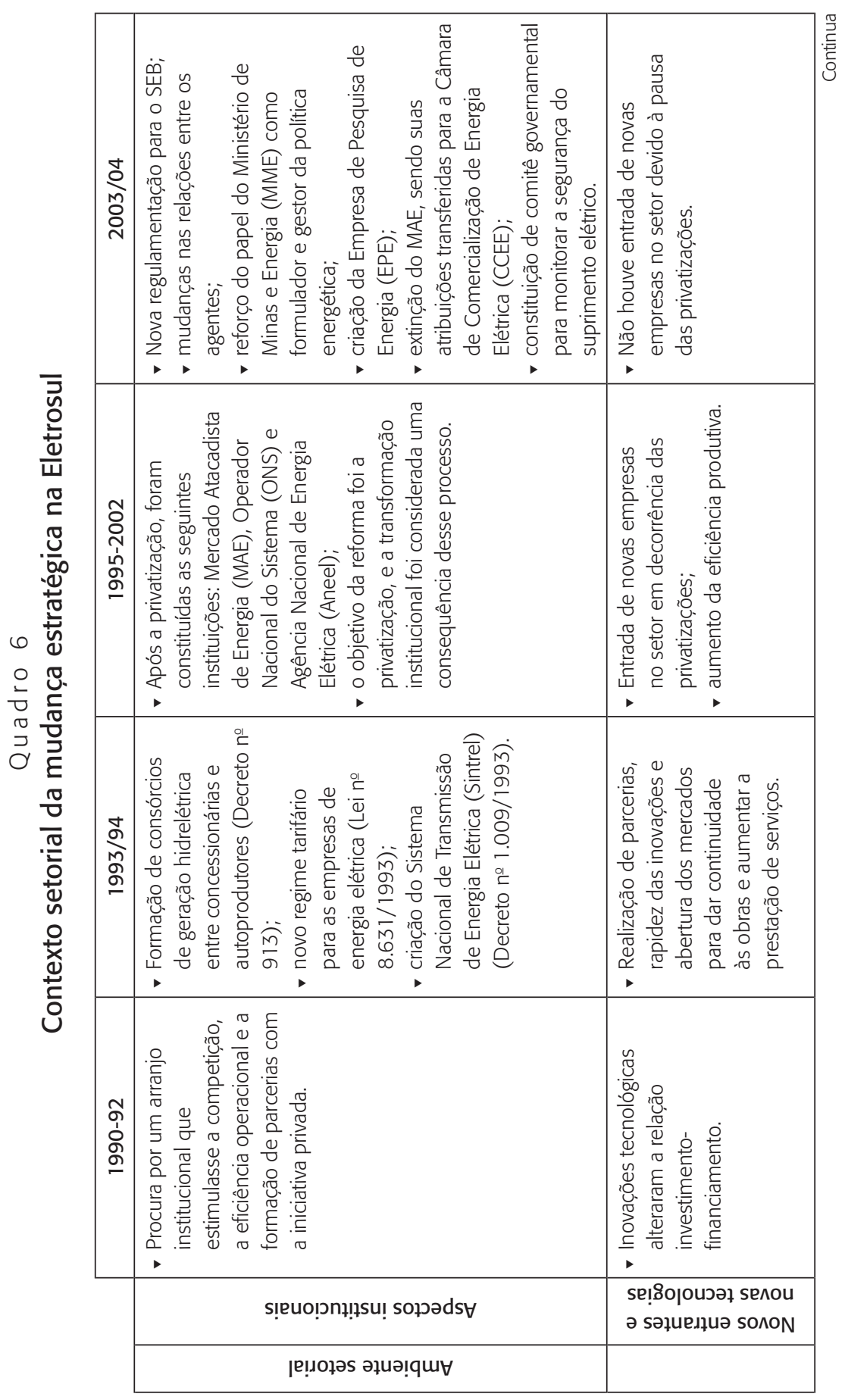




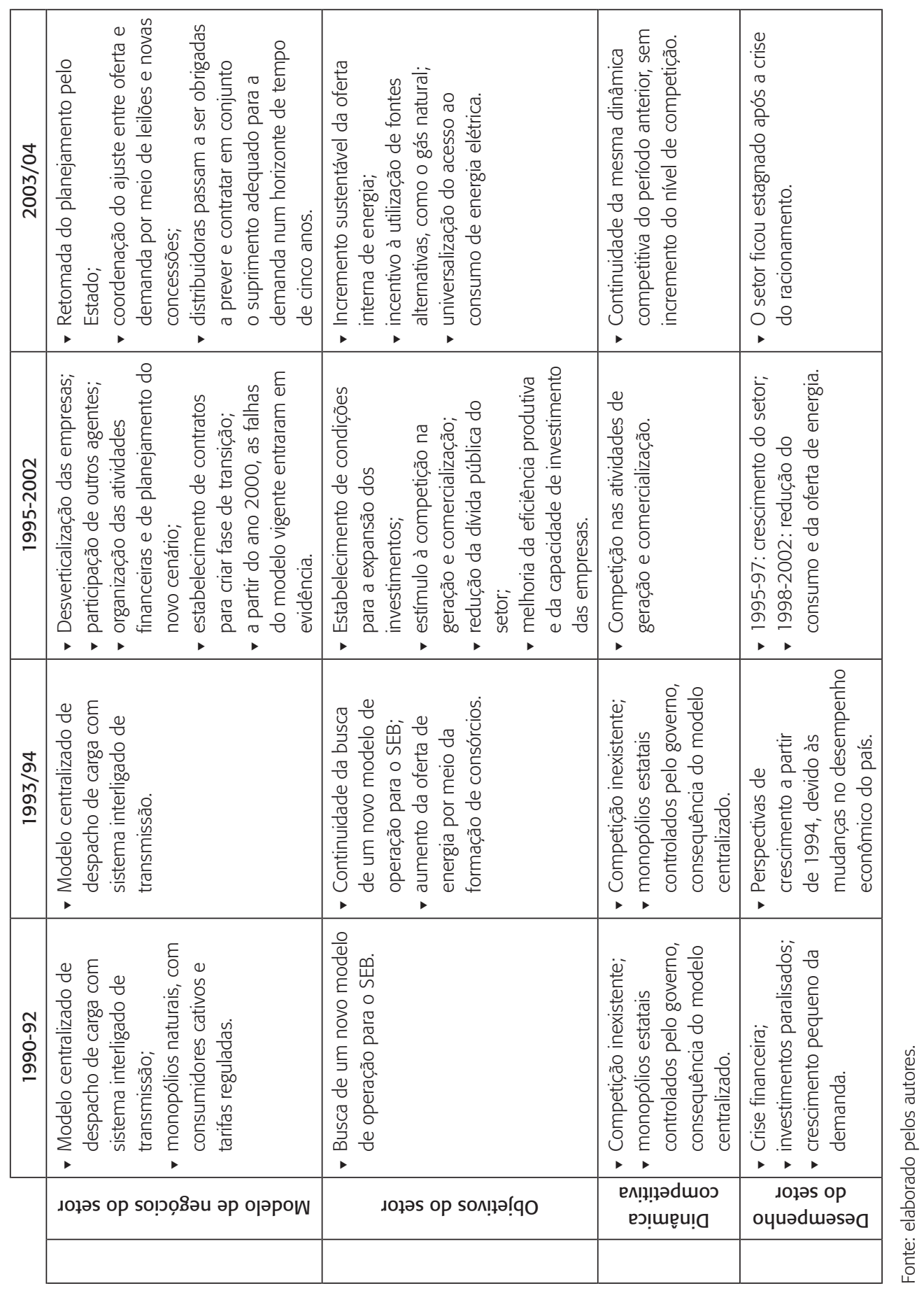


Em função do corte dos gastos, da Lei no 8.631 e das condições favoráveis da economia brasileira com a implantação do Plano Real, no período 1993/94 a empresa conseguiu alcançar uma posição de destaque no SEB. Além disso, as modificações das normas do setor permitiram a realização de parcerias que fizeram com que a Eletrosul procurasse alternativas para a captação de recursos para implementar empreendimentos essenciais para sua região de atuação. A empresa também procurou estabelecer estratégias e ações voltadas para a ampliação do mercado no âmbito do Mercosul, sempre atenta às condições do macroambiente e do ambiente setorial, com o objetivo de alcançar maior eficiência econômica. Dessa forma, continuou desenvolvendo empreendimentos que visavam à sua expansão e também iniciou estudos e projetos que estavam relacionados ao desenvolvimento de capacidades já existentes.

Em função do fraco desempenho da economia e do SEB no período 19952002, a firma obteve um grau de inadimplência de 9,1\% de seus ativos no ano de 1995, acumulando um grande prejuízo. Posteriormente, no período 19962002, a empresa não acumulou mais prejuízos, fechando o ano de 2002 com um lucro de $\mathrm{R}$ \$ 58,3 milhões. Nesse período a firma passou por algumas transformações, como sua inclusão no PND (1995) e posteriormente sua cisão (1997), passando a ser uma empresa exclusiva de transmissão de energia elétrica.

Após a cisão, até meados de 1999, as atividades de planejamento ficaram restritas às ações operacionais, até surgirem novas regras do SEB. Após o ano de 2000, a criação de novos negócios estava relacionada à realização de consultorias; aos estudos para potenciais parcerias com empresas internacionais; à participação da Eletrosul em uma empresa de transporte de dados por meio da cessão da infraestrutura de transmissão; e aos investimentos na digitalização e no telecontrole de várias subestações, o que exigiu da empresa o desenvolvimento de capacidades.

Em 2003 a Eletrosul foi excluída do Plano Nacional de Desestatização (PND), retornando às atividades de geração. No entanto, embora os ativos da empresa fossem mais escassos do que antes de sua cisão, a firma obteve um desempenho satisfatório nos anos 2003/04, possibilitando à mesma custear os investimentos em novos negócios (equipamentos digitais, projetos de pesquisa com cooperação tecnológica) e em negócios já existentes. $\mathrm{O}$ investimento em novos negócios exigiu o desenvolvimento de capacidades que a empresa até então não possuía, como capacitação de funcionários e investimento em pesquisa e desenvolvimento.

Os objetivos da empresa nos anos 2003/04, de uma forma geral, estavam relacionados ao incremento da oferta de energia elétrica (via Sociedade de Propósito Específico - SPS) e à universalização da energia.

A Eletrosul sofreu forte influência dos aspectos macroambientais e setoriais, conforme pode ser observado no quadro 7 . 


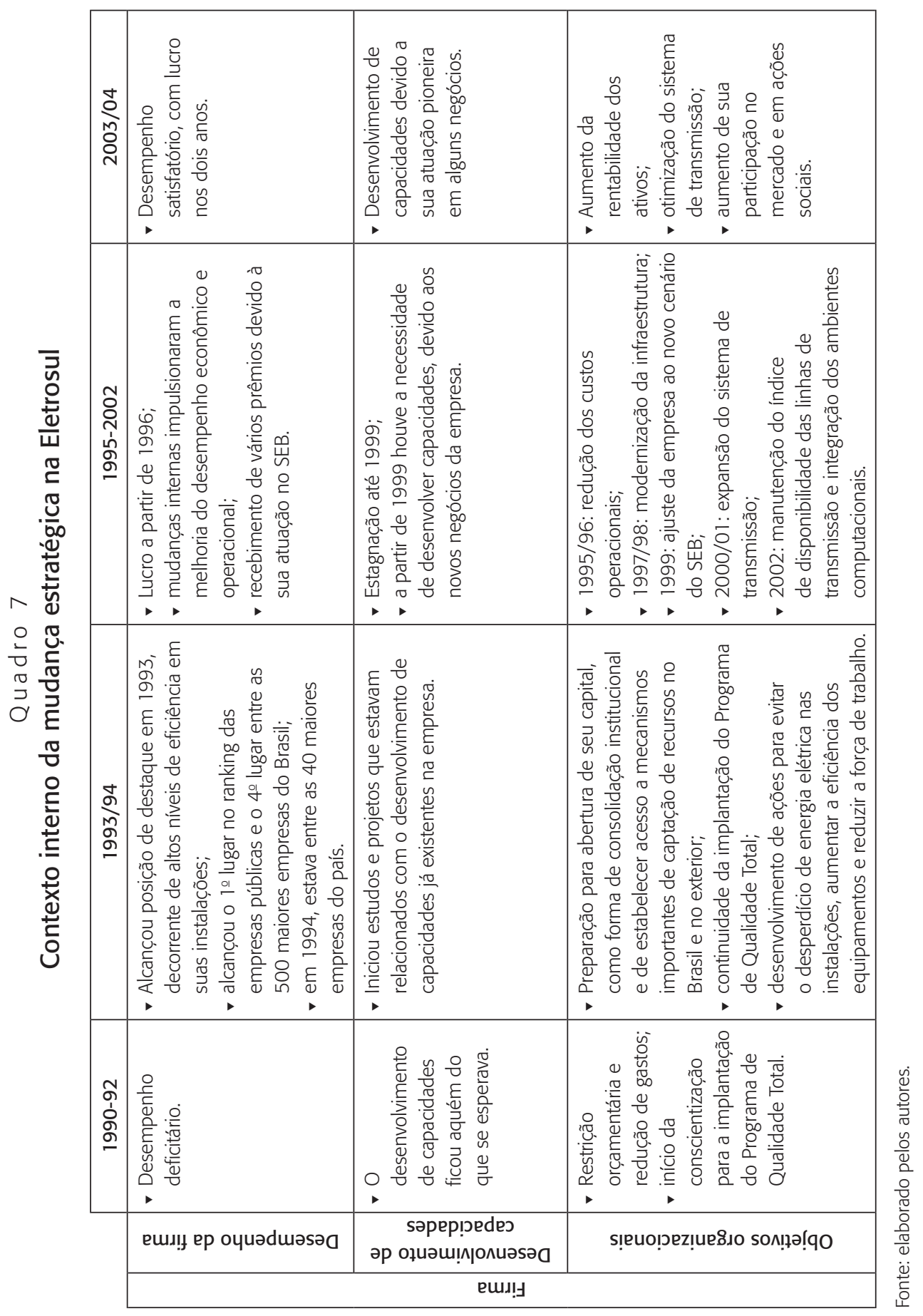


Os aspectos do contexto externo e interno influenciaram diretamente no conteúdo (estratégias realizadas) e no processo (estratégias deliberadas e emergentes) de mudança estratégica na empresa, conforme pode ser observado no quadro 8.

Ao analisar o quadro 8, pode-se verificar que os aspectos do contexto externo exerceram impacto direto sobre a empresa e suas estratégias. Em relação ao conteúdo das estratégias realizadas, foi possível identificar ações de exploração e explotação, conforme a tipologia de March (1991). A análise em cada período revela os dois tipos de ações, entre as quais destacam-se as seguintes:

$\checkmark$ principais ações estratégicas no período 1990-92: implementação do Programa de Qualidade e de 95\% das ações previstas no Plano de Gestão, e continuidade de obras de geração por meio de parcerias. Essas ações estavam condizentes com aquilo que já vinha sendo executado pela empresa, portanto, estavam dentro do escopo da atual estratégia da firma, caracterizando-se como ações estratégicas de explotação;

\ principais ações estratégicas no período 1993/94: desenvolvimento do núcleo de prestação de serviços, consolidação de parcerias e conclusão de obras. As duas primeiras representavam ações completamente novas para a empresa, que estavam fora do escopo de sua estratégia atual. Por isso, foram classificadas como ações estratégicas de exploração.

v Principais ações estratégicas no período 1995-2002: expansão do sistema de transmissão e continuidade do núcleo de prestação de serviços. Essas representavam ações estratégicas de explotação, que estavam dentro do escopo da atual estratégia da empresa.

、 Principais ações estratégicas no período 2003/04: expansão pela realização de investimentos em negócios novos e em negócios já existentes. Essas ações estavam relacionadas tanto à exploração quanto à explotação. Explotação para os investimentos em negócios existentes e exploração para os novos investimentos.

As ações estratégicas realizadas causaram uma série de impactos na firma e foram provenientes tanto de processos deliberados quanto de processos emergentes. 


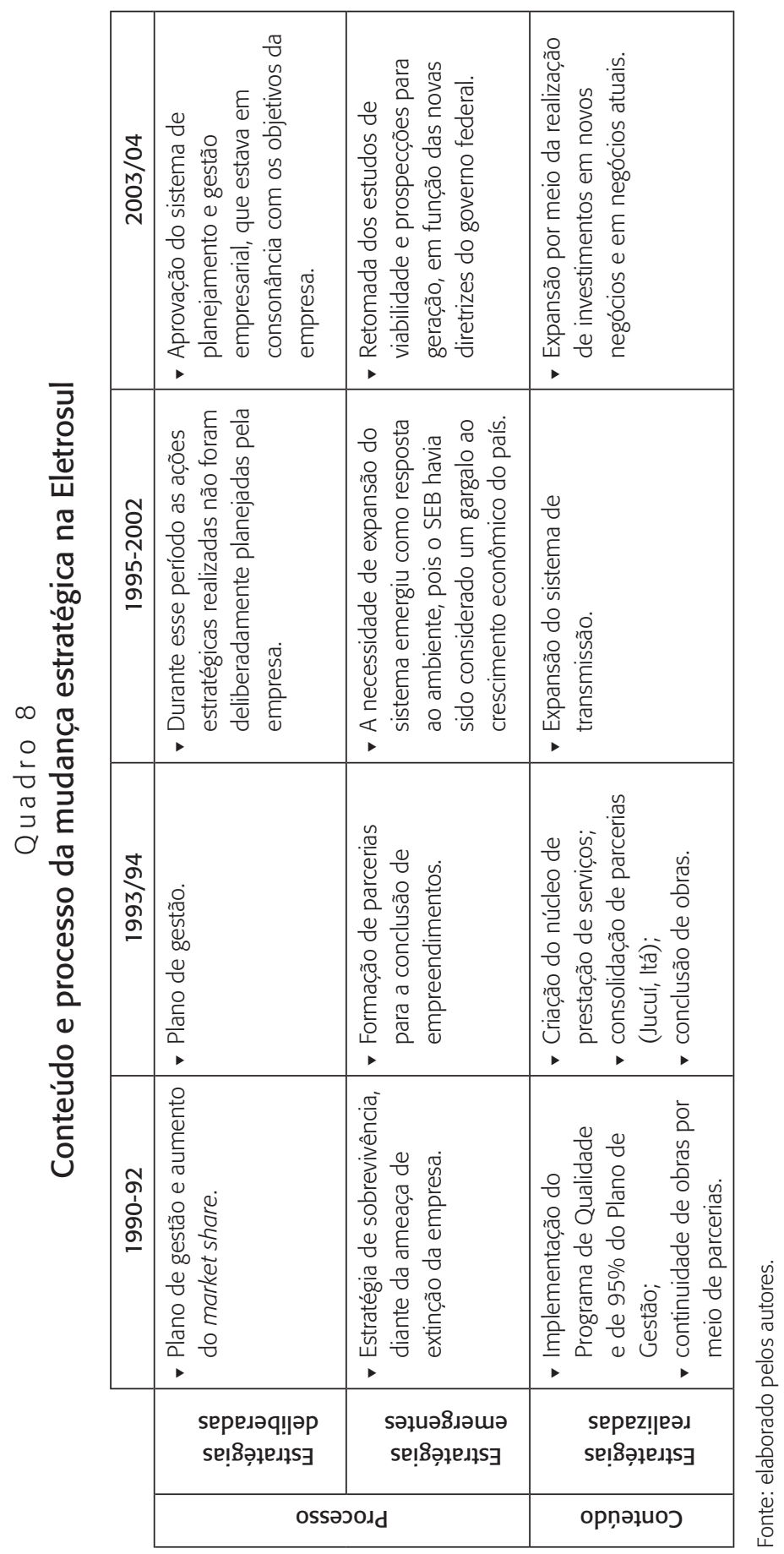




\subsection{Discussão de resultados}

Após a análise do contexto, do conteúdo e do processo de mudança estratégica, pôde-se constatar a existência de um relacionamento dinâmico entre essas três dimensões na trajetória da Eletrosul, conforme pode ser observado na figura 2, que mostra os principais eventos estratégicos ocorridos no período de análise, suas inter-relações e seus impactos, proporcionando uma visão integrada das três dimensões da mudança estratégica preconizadas por Pettigrew (1987).

Contexto, conteúdo e processo da mudança estratégica na Eletrosul

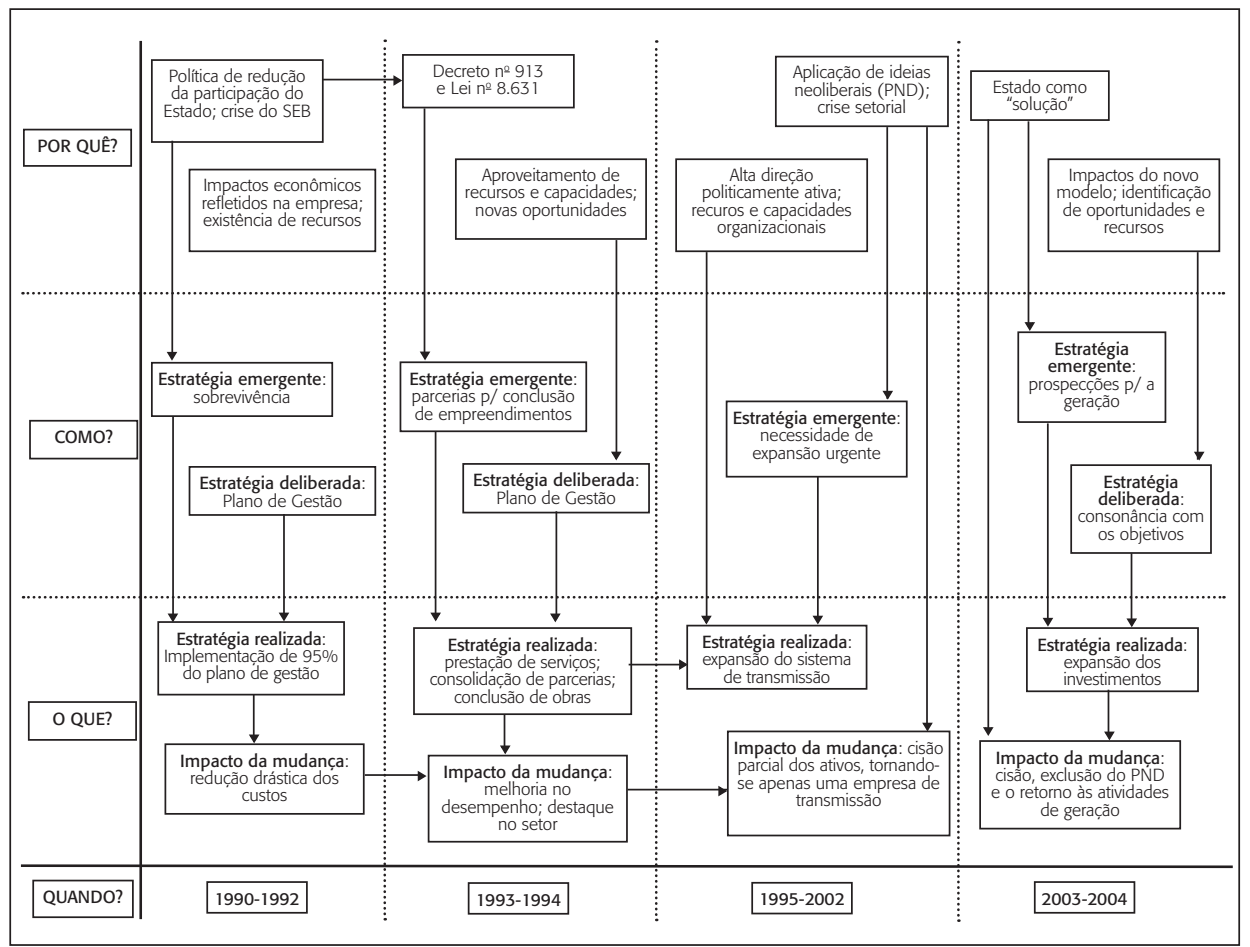

Fonte: Elaborada pelos autores.

As interações entre contexto (por quê?), conteúdo (o quê?) e processo (como?), apresentadas na figura 2, revelaram os principais impactos da mudança estratégica na empresa que ocorreram durante o período de análise. Esses impactos são discutidos a seguir. 
a) 1990-92: redução drástica dos custos.

Esse impacto foi consequência de estratégias de explotação que foram realizadas de forma deliberada e emergente pela firma. As ações realizadas pela empresa estavam voltadas para a implementação do Plano de Gestão que foi elaborado deliberadamente para cumprir os objetivos do governo federal. O Plano de Gestão pôde ser considerado uma estratégia de sobrevivência e tinha como fundamento básico a redução de custos. Esse objetivo foi plenamente atingido, uma vez que praticamente todas as ações do plano foram implantadas, fator que foi decisivo para evitar a extinção da empresa. As estratégias emergentes de expansão do mercado vislumbravam apenas a conclusão de determinadas obras, como a Usina Hidrelétrica de Jorge Lacerda/SC e a Usina Hidrelétrica de Itá/SC (que foi concluída no período posterior).

b) 1993/94: melhoria no desempenho, proporcionando uma posição de destaque no setor.

A melhoria no desempenho da empresa foi uma consequência de ações de exploração relacionadas à busca de parcerias para consolidar os investimentos já iniciados. Essas ações estratégicas de exploração surgiram de forma emergente, em função do Decreto nํ 913 que possibilitava às empresas a realização de parcerias. Já a estratégia de "conclusão de obras" foi deliberada para o alcance das diretrizes e das políticas do período e foi implementada em função da intenção gerencial de realmente realizar tal estratégia, fazendo com que a empresa se tornasse competitiva e mantivesse sua posição no mercado.

c) 1995-2002: cisão parcial dos ativos, tornando-se apenas uma empresa de transmissão.

Nesse período não houve nenhuma atividade de planejamento formal e prospecção estratégica; portanto, a mudança foi uma consequência de ações realizadas que não foram deliberadamente planejadas pela empresa. Tais ações foram guiadas pelas condições ambientais do contexto externo e implementadas de forma emergente pela firma, caracterizando-se como ações estratégicas de explotação. Nesse período teve início o processo de privatização do setor e, consequentemente, a desverticalização das empresas. Assim, a mudança na empresa foi fundamentalmente guiada pela força macroambiental que a levou a se tornar uma empresa exclusivamente de transmissão. A parte relativa à geração de energia fora vendida para o setor privado. O SEB foi considerado um dos gargalos do crescimento econômico devido à falta de investimentos no setor, o que se traduziu na crise de 
abastecimento de energia elétrica em 2001. Nesse período havia a necessidade de investimentos tanto na geração quanto na transmissão, o que repercutiu nas estratégias realizadas pela empresa (expansão do sistema de transmissão). É conveniente ressaltar que a empresa, a partir de 1999, também deu continuidade a algumas estratégias que já haviam sido realizadas em período passado, como consultorias para empresas públicas e privadas, manutenção de empreendimentos e participação na Eletronet (empresa de transporte de dados criada por meio da cessão da infraestrutura do sistema de transmissão), sendo caracterizadas como ações de explotação.

d) 2003/04: exclusão do Plano Nacional de Desestatização e retorno às atividades de geração.

A exclusão do PND foi uma consequência das transformações que ocorreram na ideologia política, nos aspectos institucionais, no modelo de negócios do setor e também nos objetivos setoriais. Dessa forma, a mudança foi guiada por uma força externa que influenciou na estratégia emergente de "prospecções para a geração" que, junto com uma estratégia deliberada pela empresa, levou à realização da estratégia de "expansão dos investimentos". A realização dessa estratégia só foi possível em função de seu retorno à atividade de geração, sendo esta a principal mudança do período. Foi possível verificar também um alinhamento da empresa com os objetivos e com a ideologia política do governo, havendo, inclusive, esforços de ambas as partes para atrair recursos para a infraestrutura, combinando, dessa forma, as diretrizes do governo federal com os recursos e as capacidades organizacionais.

De uma forma geral, foi possível verificar que os aspectos regulatórios tiveram uma grande influência sobre a mudança estratégica na empresa. Os aspectos institucionais determinaram as regulações específicas aplicadas ao SEB e à Eletrosul. Tais aspectos também influenciaram na entrada de novas empresas no mercado, o que, na verdade, era uma consequência das privatizações. Esses aspectos influenciaram em todo o processo de adaptação da organização. Além disso, o desempenho do setor tinha um impacto direto sobre a Eletrosul, isto é, se fosse negativo, a empresa passava por crises em decorrência disso.

Enfim, todos os aspectos do macroambiente e do ambiente setorial apresentados nos quadros 5 e 6 afetaram significativamente a Eletrosul e, consequentemente, a mudança estratégica na organização. No entanto, a Eletrosul 
também conseguiu influenciar nas mudanças, principalmente pela intenção dos tomadores de decisão em levar a cabo as estratégias da empresa. Em outras palavras, pode-se dizer que a adaptação estratégica da Eletrosul no período 1990-2004 ocorreu em função das pressões exercidas pelo ambiente e também em função da intenção dos gerentes, o que caracteriza a natureza voluntarista e determinista dos processos de mudança. Apenas no período 1995-2002 a mudança na empresa foi essencialmente determinista, pois sua inclusão no PND e sua consequente cisão ocorreram de forma involuntária, tendo sido determinadas pelas pressões do ambiente externo. Além disso, as pressões do ambiente externo da Eletrosul, que é considerado altamente institucionalizado, influenciaram nas ações estratégicas realizadas pela empresa, restringindo suas opções estratégicas, mas sem eliminá-las completamente.

\section{Conclusões}

O período que contemplou esta pesquisa (1990-2004) foi de grande turbulência para o setor elétrico e também para a firma em análise, fazendo com que várias mudanças surgissem para modificar o comportamento estratégico da Eletrosul e sua competitividade. Muitas mudanças foram impostas pelo ambiente externo e outras foram possíveis graças ao empenho da empresa em realmente implementar determinadas estratégias que garantiram, inclusive, sua sobrevivência. Em vários momentos, o pessoal responsável pela tomada de decisão estratégica soube interpretar as pressões exercidas pelo ambiente externo, transformando tais pressões em estratégias realizadas que levaram à mudança estratégica na organização. Dessa forma, pode-se concluir que a mudança estratégica na Eletrosul ocorreu por meio de um processo de intenção gerencial (voluntarismo) e também por meio de um processo de seleção ambiental e pressão institucional (determinismo).

A identificação das estratégias emergentes permitiu reconhecer a pressão que o contexto externo (macro e setorial) exerceu sobre as ações estratégicas realizadas pela empresa, caracterizando o determinismo ambiental. As estratégias que emergiram como resposta ao ambiente no período 1990-92 buscavam garantir a sobrevivência da empresa, pois o governo federal tinha a intenção de extinguir a Eletrosul. Para que isso não acontecesse, a empresa teria que, no mínimo, manter-se no mercado. Nos anos 1993/94, o ambiente pressionou a conclusão de alguns empreendimentos, principalmente em função da deliberação do Decreto no ${ }^{\circ}$ 913, que permitiu a formação de parcerias 
com o setor privado e com outras concessionárias. Nos anos 1995-2002, a estratégia emergente estava relacionada com a necessidade de expansão do sistema elétrico, principalmente em função do péssimo desempenho do setor elétrico na ocasião. Finalmente, nos anos 2003/04, a estratégia que emergiu do ambiente estava relacionada à saída da empresa, de forma involuntária, do Plano Nacional de Desestatização, fazendo com que fosse necessário desenvolver estudos de viabilidade de novos empreendimentos e prospecções para futuros aproveitamentos hidrelétricos.

A visão integrada da mudança estratégica na Eletrosul foi possível por meio da utilização do modelo de Pettigrew (1987), que permitiu compreender com profundidade a interação dinâmica entre contexto, conteúdo e processo. À medida que são associadas novas categorias de análise a cada uma das três dimensões, o modelo de Pettigrew (1987) demonstra sua validade como um framework metodológico robusto e contemporâneo para os estudos organizacionais.

Diante de um ambiente tão turbulento, conhecer a trajetória estratégica da empresa passa a ser uma questão fundamental para que a estratégia possa ser gerenciada de uma forma dinâmica, condizente com seu mercado. Assim, sugere-se que sejam estudados outros aspectos do contexto, do conteúdo e do processo na empresa foco de estudo e em outras organizações do SEB. Por exemplo, no contexto interno podem-se utilizar outras variáveis para analisar o desempenho da firma, seguindo a lógica do Balanced Scorecard (BSC), que vai além do desempenho financeiro ao incluir o desempenho em relação aos clientes, à aprendizagem e aos processos internos. Outro possível caminho para a continuidade da pesquisa é a verificação das relações entre contexto, conteúdo e processo em um universo mais amplo, utilizando uma amostra representativa das empresas do SEB. Uma análise quantitativa poderia proporcionar o entendimento dos possíveis padrões de mudança estratégica das empresas do setor.

Enfim, o SEB é considerado um setor estratégico e de fundamental importância para o crescimento e desenvolvimento econômico da nação. É interessante destacar que, além das mudanças setoriais que foram relatadas, o setor ainda continua sendo foco de transformações, muitas vezes em decorrência dos interesses políticos de cada governo. Sendo a Eletrosul uma empresa estatal, esta recebe influência direta do governo federal, que, por sua vez, estabelece novas regras a cada ameaça de crise no setor. 


\section{Referências}

AGARWAL, Rajshree; HELFAT, Constance E. Strategic renewal of organizations. Organization Science, v. 20, n. 2, p. 281-293, 2009.

ASTLEY, Graham W.; VAN DE VEN, Andrew H. Central perspectives and debates in organizational theory. Administrative Science Quarterly, v. 28, n. 2, p. 245-273, 1983.

AZEREDO, Luiz Cezar Loureiro. Investimento em infraestrutura no plano plurianual (PPA) 2004-2007: uma visão geral. Texto para discussão, Brasília, n. 1024, jun. 2004. 46 p. Disponível em: <www.ipea.gov.br>. Acesso em: 5 abr. 2005.

BARNEY, Jay B. Is the resource based "view" a useful perspective for strategic management research? Yes. Academy of Management Review, v. 25, n. 1, p. 41-56, 2001.

BERNARDES, Patrícia. Incertezas na decisão estratégica de investimento na geração de energia elétrica. 243 f. Tese (doutorado em administração) — Faculdade de Ciências Econômicas da Universidade Federal de Minas Gerais, UFMG, Belo Horizonte, 2003.

BEUGELSDIJK, Sjoerd; SLANGEN, Arjen; HERPEN, Marco Van. Shapes of organizational change: the case of Heineken Inc. Journal of Organizational Change Management, v. 15, n. 3, p. 311-326, 2002.

BOSQUETTI, Marcos Abilio; DORIA, Ricardo José; FERNANDES, Bruno H.R. Ambiente e empresas do setor elétrico brasileiro: um estudo comparativo de múltiplos casos. Revista Alcance, v. 12, n. 1, p. 99-118, jan./abr. 2005.

CARTEMOL, Fabrício. Inovações e contestabilidade: algumas considerações sobre a eficiência econômica. Revista do BNDES, v. 11, n. 22, p. 123-149, dez. 2004.

CHANDLER JR., A.D. Strategy and structure: chapters in the history of the American industrial enterprise. Cambridge, Mass: The M.I.T. Press, Massachusetts Institute of Technology, 1962.

CHILD, John; SMITH, Chris. The context and process of organizational transformation: Cadbury limited in its sector. Journal of Management Studies, v. 24, n. 6, p. 565-593, nov. 1987.

CORAM, Ron; BURNES, Bernard. Managing organizational change in the public sector: lessons from privatization of the Property Service Agency. The International Journal of Public Sector Management, v. 14, n. 2, p. 94-110, 2001. 
FIOCCA, Demian. As parcerias público-privadas na estratégia econômica brasileira. In: SEMINÁRIO INTERNACIONAL DE FUNDOS DE PENSÃO, 2, Rio de Janeiro, 2004. Disponível em: <www.planejamento.gov.br>. Acesso em: 15 jul. 2005.

GOMES, João Paulo Pombeiro; VIEIRA, Marcelo Milano Falcão. O campo da energia elétrica no Brasil de 1880 a 2002. RAP — Revista de Administração Pública, Rio de Janeiro, v. 43, n. 2, p. 295-321, 2009.

HAILEY, Veronica H.; BALOGUN, Julia. Devising context sensitive approaches to change: the example of Glaxo Wellcome. Long Range Planning, v. 35, n. 2, p. 153 178, 2002.

HUTT, M.D.; WALKER, B.A.; FRANKWICK, L.G. Hurdle the crossfunctional barriers to strategic change. Sloan Management Review, v. 36, n. 3, p. 22-30, Spring 1995.

LAWRENCE, Paul R.; LORSCH, Jay W. O desenvolvimento de organizações: diagnóstico e ação. São Paulo: Edgard Blücher, 1972.

MARCH, James G. Exploration and exploitation in organizational learning. Organization Science, v. 2, n. 1, p. 71-86, 1991.

MASSINI, Silvia et al. The evolution of organizational routines among large Western and Japanese firms. Research Policy, v. 31, n. 8/9, p. 1333-1348, 2002.

MILLER, Danny; FRIESEN, Peter H. Structural change and performance: quantum versus piecemeal-incremental approaches. Academy of Management Journal, v. 25, n. 4, p. 867-892, 1982.

MINTZBERG, Henry. Patterns in strategy formation. Management Science, v. 24, n. 9, p. 934-948, maio 1978.

MINTZBERG, Henry; AHLSTRAND, Bruce; LAMPEL, Joseph. Safári de estratégia: um roteiro pela selva do planejamento estratégico. Porto Alegre: Bookman, 2000.

MINZTBERG, Henry; WESTLEY, Frances. Cycles of organization change. Strategic Management Journal, v. 13, n. 8, p. 39-59, 1992.

NELSON, Lindsay; DOWLING, Peter J. Electricity industry reform: a case analysis in Australia. Journal of Organizational Change Management, v. 11, n. 6, p. 481495, 1998.

OLIVEIRA, Brigitte Renata B. et al. Processo de formação de estratégias internacionais na fruticultura brasileira: uma abordagem integrada. Cadernos Ebape.BR, Rio de Janeiro, v. 7, n. 2, p. 295-313, 2009.

PETERAF, Margaret A. The cornerstones of competitive advantage: a resource based view. Strategic Management Journal, v. 14, n. 3, p. 179-191, 1993. 
PETTIGREW, Andrew et al. Shaping strategic change. London: Sage, 1992.

PETTIGREW, Andrew M. Context and action in the transformation of the firm. Journal of Management Studies, v. 24, n. 6, p. 649-670, 1987.

PETTIGREW, Andrew M. Examining change in the long-term context of culture and politics. In: PENNINGS, J.M. et al. Organizational strategy and change: new views on formulating and implementing strategic decisions. San Francisco: Jossey-Bass, 1985. p. 269-318.

PINHEIRO, Armando Castelar; GIAMBIAGI, Fabio. Os antecedentes macroeconômicos e a estrutura institucional da privatização no Brasil. In: PINHEIRO, Armando Castelar; FUKASASKU, Kiichiro (Org.). Privatização no Brasil: o caso dos serviços de utilidade pública. Rio de Janeiro: BNDES, 2000. p. 14-43.

PIRES, José Cláudio Linhares. Desafios da reestruturação do setor elétrico brasileiro. Texto para discussão, Rio de Janeiro, n. 76, mar. 2000. 45 p. Disponível em: <www.bndes.gov.br>. Acesso em: 22 jul. 2002.

QUINN, James B.; VOYER, John. Incrementação lógica: administrando a formação da estratégia. In: MINTZBERG, Henry; QUINN, James B. O processo da estratégia. 3. ed. Porto Alegre: Bookman, 2001. p. 109-114.

SCHEIN, Edgar H. Psicologia organizacional. 3. ed. Rio de Janeiro: Prentice Hall do Brasil, 1982.

SOUZA, Paulo Roberto Cavalcanti de. Evolução da indústria de energia elétrica brasileira sob mudanças no ambiente de negócios: um enfoque institucionalista. $171 \mathrm{f}$. Tese (doutorado em engenharia de produção) - Programa de Pós-Graduação em Engenharia de Produção, Universidade Federal de Santa Catarina, Florianópolis, 2002.

VAN DE VEN, Andrew H. Suggestions for studying strategy process: a research note. Strategic Management Journal, v. 13, n. 5, p. 169-188, 1992.

VELASCO JÚNIOR, Licínio. A economia política das políticas públicas: fatores que favoreceram as privatizações no período 1985-94. Texto para discussão, Rio de Janeiro, n. 54, abr. 1997a. 59 p. Disponível em: <www.bndes.gov.br>. Acesso em: 19 nov. 2003.

VELASCO JÚNIOR, Licínio. A economia política das políticas públicas: as privatizações e a reforma do Estado. Texto para discussão, Rio de Janeiro, n. 55, maio $1997 \mathrm{~b}$. 42 p. Disponível em: <www.bndes.gov.br>. Acesso em: 22 jul. 2002.

VINHAES, Élbia A.S. Estrutura de governança e comportamento estratégico em sistemas elétricos reestruturados: uma abordagem institucional do poder de mercado na indústria de energia elétrica brasileira. $234 \mathrm{f}$. Tese (doutorado em engenharia 
de produção) - Programa de Pós-Graduação em Engenharia de Produção, Universidade Federal de Santa Catarina, Florianópolis, 2003.

VOLBERDA, Henk W.; BADEN-FULLER, Charles; VAN DEN BOSCH, Frans A.J. Mastering strategic renewal: mobilizing renewal journeys in multi-unit firms. Long Range Planning, v. 34, n. 2, p. 159-178, 2001.

YIN, Robert K. Case study research: design and methods. 2. ed. Sage: Thousand Oaks, 1994. 